\title{
Clonazepam-associated Bradycardia in a Disabled Elderly Woman with Multiple Complications
}

\author{
Hidetomo Maruyoshi ${ }^{1}$, Natsue Maruyoshi ${ }^{2}$, Motone Hirosue ${ }^{3}$, \\ Komei Ikeda ${ }^{4}$ and Masaaki Shimamoto ${ }^{3}$
}

\begin{abstract}
:
We herein report an 87-year-old woman who was taking clonazepam at $1.5 \mathrm{mg} / \mathrm{day}$. She was hospitalized with an old cerebral infarction complicated with symptomatic epilepsy, dementia, dyslipidemia, and chronic cholecystitis. Electrocardiogram revealed severe bradycardia at 31 beats $/ \mathrm{min}$. The bradycardia disappeared on day 3 after clonazepam withdrawal, although the serum clonazepam level had been within normal limits. She was diagnosed with clonazepam-associated bradycardia, which was likely related to the potential calcium channel-blocking properties of clonazepam. Because of age-related pharmacokinetic and pharmacodynamic changes, the adverse effects of clonazepam should be considered, especially in disabled elderly individuals with multiple comorbidities.
\end{abstract}

Key words: adverse drug event, benzodiazepine, bradycardia, clonazepam, disability, elderly

(Intern Med 56: 2301-2305, 2017)

(DOI: 10.2169/internalmedicine.8234-16)

\section{Introduction}

Clonazepam, a benzodiazepine derivative, is frequently used in a variety of clinical situations, such as to treat epilepsy, anxiety, and myoclonus, even in elderly patients (1-3). We herein report a case involving a disabled elderly woman with multiple complications presenting with a clonazepamassociated episode of severe bradycardia.

\section{Case Report}

An 87-year-old woman was admitted to the geriatric longterm care ward of our hospital with an old cerebral infarction complicated with symptomatic epilepsy. She could not communicate at all because of severe dementia; her mini mental state examination score was $0 / 30$. She needed assistance for all activities of daily living. Because of her progressive dysphagia, she had received her nutrition through a nasogastric tube since the 82 years of age but was switched to total parenteral nutrition via the central veins following an episode of severe cholecystitis associated with gallstones at 86 years of age. Further complications included dyslipidemia, bilateral hydronephrosis due to renal stones, and a history of pyelonephritis. Clonazepam had been administered ( $0.5 \mathrm{mg}$, three times a day) for symptomatic epilepsy for 53 months through her nasogastric tube to treat symptomatic epilepsy. Six months previously, her serum trough clonazepam level had been within normal limits [25.6 ng/mL; reference range: $20-70 \mathrm{ng} / \mathrm{mL}$ (4)]. Additionally, ursodeoxycholic acid $(300 \mathrm{mg} /$ day $)$ and sucralfate $(2,700 \mathrm{mg} /$ day $)$ had been administered; however, she had not received donepezil, digitalis, calcium antagonists, or beta adrenergic blockers. Her pulse rate was consistently 50-70 beats/min; however, transient bradycardia (45-50 beats/min) had been observed twice a week for approximately 1 month. During her hospitalization, she developed severe bradycardia.

She was small in stature; her height, body weight, and body surface area were $145 \mathrm{~cm}, 42 \mathrm{~kg}$, and $1.30 \mathrm{~m}^{2}$, respectively. She opened her eyes in response to our voices but showed no response to commands at baseline. On a physical examination, her vital signs were as follows: blood pressure $121 / 67 \mathrm{mmHg}$, pulse rate 32 beats/min, respiratory rate 18 breaths/min, body temperature $36.4^{\circ} \mathrm{C}$, and oxygen satura-

${ }^{1}$ Department of Cardiology, Shimamoto Hospital, Japan, ${ }^{2}$ Department of Neurology, Shimamoto Hospital, Japan, ${ }^{3}$ Department of Internal Medicine, Shimamoto Hospital, Japan and ${ }^{4}$ Department of Neurological Surgery, Shimamoto Hospital, Japan

Received: September 7, 2016; Accepted: January 24, 2017; Advance Publication by J-STAGE: August 10, 2017

Correspondence to Dr. Hidetomo Maruyoshi, hmaruyos@nifty.com 


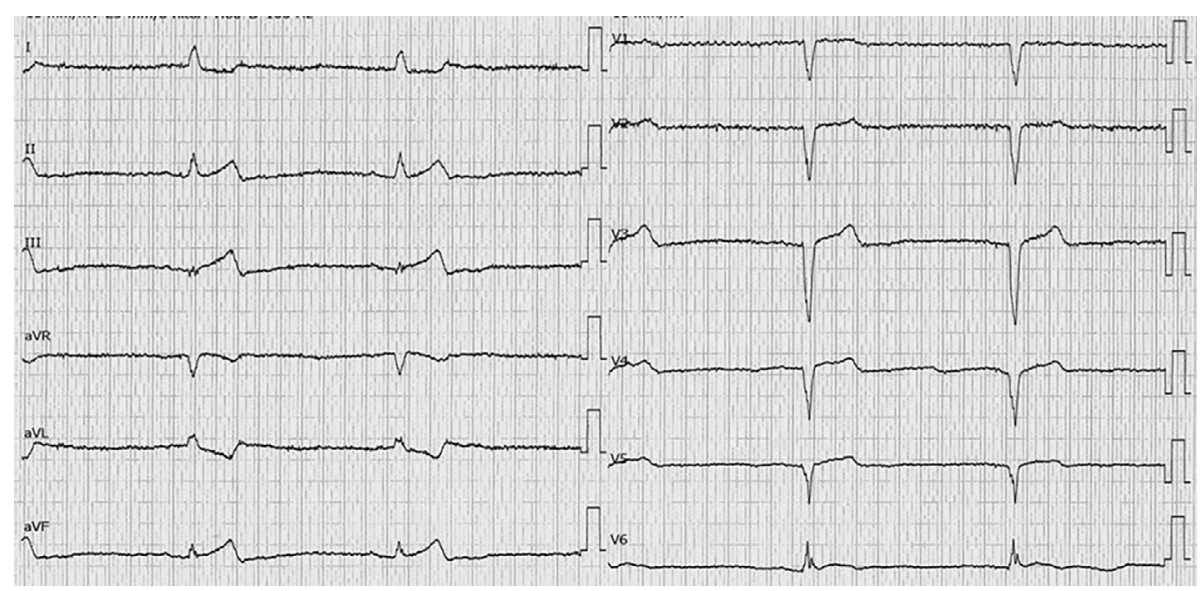

Figure 1. Electrocardiogram at the onset of severe bradycardia recorded $4 \mathrm{~h}$ after the last intake of clonazepam $(0.5 \mathrm{mg})$. Severe bradycardia ( 31 beats $/ \mathrm{min}$ ) is shown with a first-degree atrioventricular block. Altered P wave shape; ST elevation in leads II, III, aVF, and V6; and regression of the R wave in leads V4-6 compared with a previous record are also observed (Fig. 2). The altered $P$ wave contour may suggest atrial escape beat. The PR interval, QRS duration, and QT/QTc interval were $230 \mathrm{msec}$, $126 \mathrm{msec}$, and 562/429 msec, respectively.

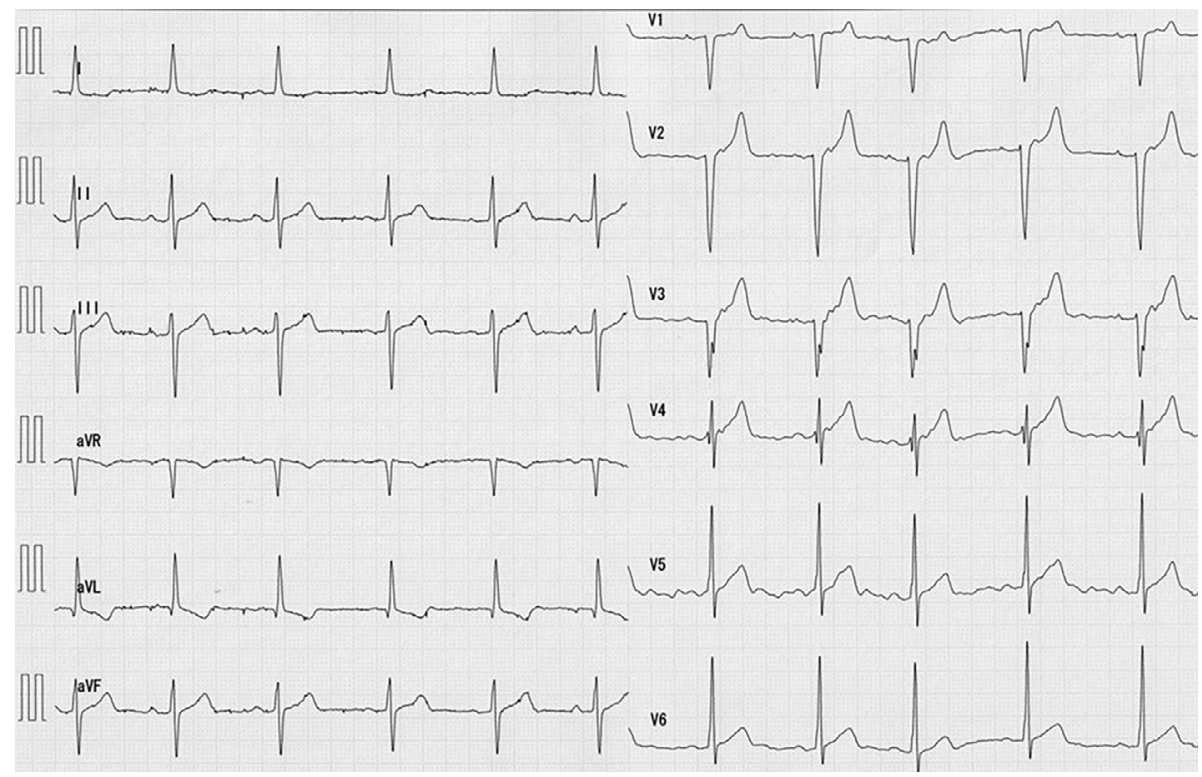

Figure 2. Electrocardiogram recorded 22 months before the occurrence of bradycardia. The heart rate is 63 beats $/ \mathrm{min}$. The presence of multiple $P$ wave contours may suggest sick sinus syndrome. Poor $R$ wave progression in leads V1-3 is also observed. The PR interval, QRS duration, and QT/QTc interval are $184 \mathrm{msec}, 106 \mathrm{msec}$, and $432 / 440 \mathrm{msec}$, respectively.

tion $98 \%$ on room air. Her heart sounds were almost regular with a slow rhythm, and there were no gallops or murmurs. Her lungs were clear on auscultation. Pitting edema was identified on the posterior side of both lower limbs.

An electrocardiogram recorded 4 hours after the last intake of clonazepam $(0.5 \mathrm{mg})$ revealed severe bradycardia (Fig. 1, 3B). An altered $\mathrm{P}$ wave shape; first-degree atrioventricular block; ST elevation in leads II, III, aVF, and V6; and poor $\mathrm{R}$ wave progression in leads V4-6 were observed, compared with an electrocardiogram recorded 22 months previously (Fig. 2, 3A). Chest radiograph revealed cardiomegaly (cardiothoracic ratio $65.5 \%$ ) with pulmonary con- gestion. An echocardiogram revealed normal contractility without asynergy and mild pulmonary hypertension; her estimated pulmonary artery systolic pressure was $43 \mathrm{mmHg}$. The laboratory data are shown in Table. Hypoalbuminemia, renal dysfunction, elevated biliary enzymes, and inflammatory reaction were shown. Dyslipidemia (hypertriglyceridemia and hypo-high-density lipoprotein (HDL) cholesterolemia), insulin resistance, subclinical hypothyroidism, and elevated $\mathrm{N}$-terminal pro-brain natriuretic peptide were also revealed. An electrolyte analysis was within the normal range. Her serum clonazepam level was within the therapeutic range $(34.8 \mathrm{ng} / \mathrm{mL})$. 
Table. Laboratory Data.

\begin{tabular}{|c|c|c|c|c|c|}
\hline $\mathrm{WBC}(/ \mu \mathrm{L})$ & 7,500 & BUN (mg/dL) & 37.7 & T-Bil (mg/dL) & 0.2 \\
\hline $\mathrm{RBC}\left(\times 10^{4} / \mu \mathrm{L}\right)$ & 373 & Cre $(\mathrm{mg} / \mathrm{dL})$ & 1.06 & AST (IU/L) & 22 \\
\hline $\mathrm{Hb}(\mathrm{g} / \mathrm{dL})$ & 12 & $\mathrm{UA}(\mathrm{mg} / \mathrm{dL})$ & 5 & ALT (IU/L) & 22 \\
\hline Hct (\%) & 35.8 & $\mathrm{Na}(\mathrm{mEq} / \mathrm{L})$ & 133 & LDH (IU/L) & 119 \\
\hline Plt $\left(\times 10^{4} / \mu \mathrm{L}\right)$ & 26 & $\mathrm{~K}(\mathrm{mEq} / \mathrm{L})$ & 5.2 & $\operatorname{ALP}(\mathrm{IU} / \mathrm{L})$ & 820 \\
\hline $\mathrm{TP}(\mathrm{g} / \mathrm{dL})$ & 6.4 & $\mathrm{Cl}(\mathrm{mEq} / \mathrm{L})$ & 99 & $\gamma$-GTP (IU/L) & 96 \\
\hline Alb (g/dL) & 3.2 & $\mathrm{Ca}(\mathrm{mg} / \mathrm{dL})$ & 9.1 & Serum Amylase (IU/L) & 53 \\
\hline T-Chol (mg/dL) & 209 & $\mathrm{Mg}(\mathrm{mg} / \mathrm{dL})$ & 1.9 & CK (U/L) & 48 \\
\hline HDL-C (mg/dL) & 28 & $\mathrm{CRP}(\mathrm{mg} / \mathrm{dL})$ & 4.13 & Urinalysis: & \\
\hline $\mathrm{TG}(\mathrm{mg} / \mathrm{dL})$ & 410 & $\mathrm{TSH}(\mu \mathrm{IU} / \mathrm{mL})$ & 10.4 & Urine Glucose & $(-)$ \\
\hline $\mathrm{ChE}$ (IU/L) & 216 & FT3 (pg/mL) & 1.9 & Occult Blood & $(++++)$ \\
\hline $\mathrm{BS}(\mathrm{mg} / \mathrm{dL})$ & 111 & FT4 (ng/dL) & 1.7 & Urine Protein & $(++)$ \\
\hline Insulin $(\mu \mathrm{U} / \mathrm{mL})$ & 20 & Serum Clonazepam (ng/mL) & 34.8 & Sediment: RBC & $>100 / \mathrm{HPF}$ \\
\hline $\mathrm{HbA} 1 \mathrm{c}(\%)$ & 5.3 & NT-pro BNP (pg/mL) & 951 & WBC & 50-60/HPF \\
\hline
\end{tabular}

The HOMA-IR was 5.48 , calculated using the following formula: Insulin $\times$ BS $/ 405$

The eGFR was $37.3 \mathrm{~mL} / \mathrm{min} / 1.73 \mathrm{~m}^{2}$, calculated using the following formula: $194 \times \mathrm{Cre}^{-1.094} \times \mathrm{Age}^{-0.287} \times 0.739$
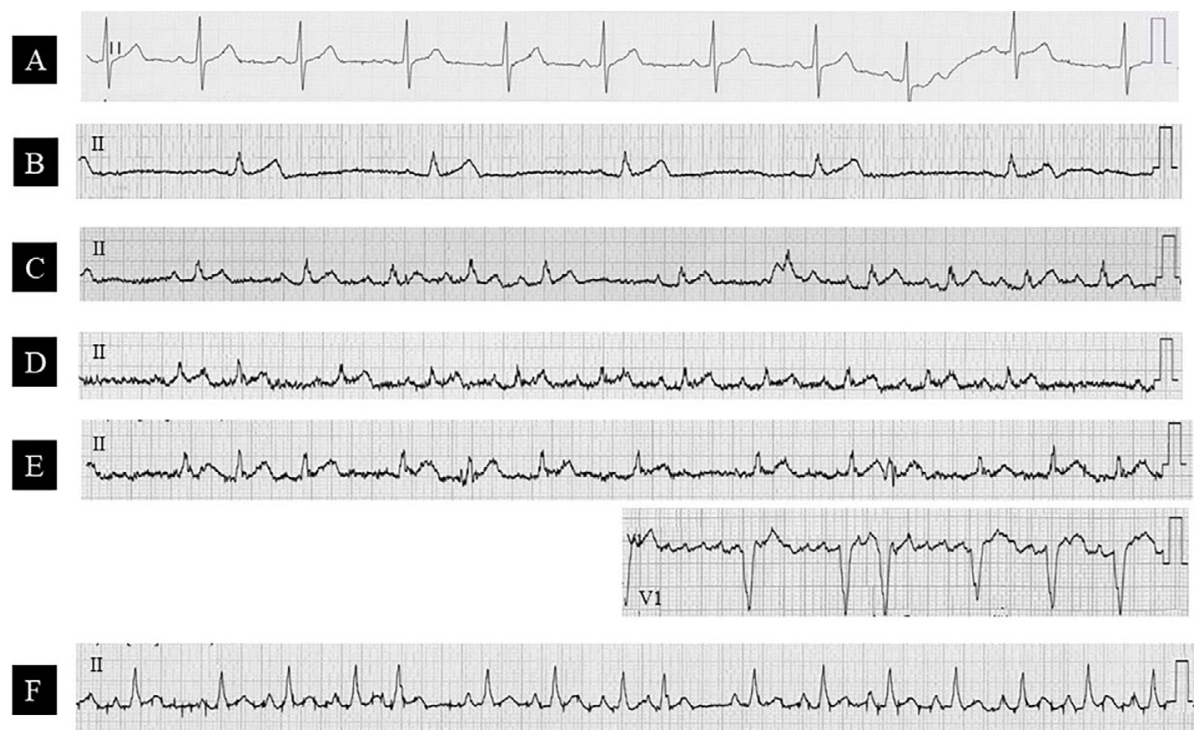

Figure 3. Time-course of electrocardiogram changes. Before (A), at onset (B), and after the withdrawal of clonazepam on day 3 (C), day 7 (D), day 20 (E: with V1 leads), and day 60 (F). Bradycardia disappeared on day 3 (C). However, ectopic atrial rhythm (C, D, F), sinoatrial block (D), and paroxysmal atrial fibrillation (E) occurred.

After the initial evaluation, only clonazepam was discontinued immediately, while other medications and fluid therapy were continued. During observation, her pulse rate at $12,24,48$, and 72 hours after the cessation of clonazepam favorably recovered to $47,53,64$, and 78 beats/min, respectively. Electrocardiogram on day 3 after clonazepam discontinuation confirmed resolution of bradycardia (Fig. 3C). A transient elevation in the body temperature $\left(37.7^{\circ} \mathrm{C}\right)$ was observed on day 4 after the discontinuation of clonazepam, which resolved quickly. The heart failure on chest radiograph and ST changes and poor $\mathrm{R}$ wave progression on electrocardiogram improved gradually. However, ectopic atrial rhythm, sinoatrial block, and paroxysmal atrial fibrillation occurred during the course of her electrocardiograms (Fig. 3C-F). Her consciousness level never changed after the withdrawal of clonazepam. She ultimately died on day 74 due to recurrent emphysematous cholecystitis accompanied by a gallbladder abscess.

\section{Discussion}

In this patient, discontinuing clonazepam improved the severe bradyarrhythmia, and we made a diagnosis of clonazepamassociated bradycardia. Although benzodiazepine-associated dysrhythmias have been reported, they are not common (5). Furthermore, bradycardia associated with clonazepam is rare. To date, two cases of arrhythmia related to clonazepam have been reported in the literature $(5,6)$. One case was a four-year-old boy presenting with an atrioventricular block associated with the excessive administration of clonazepam (5). The other case was a 74-year-old man with endstage renal disease who presented with sinus bradycardia 
caused by the interaction of amiodarone and clonazepam; the patient also had a medical history of sinus bradycardia related to diazepam (6).

Although the exact mechanisms are unknown, clonazepam may have caused sinus bradycardia by blocking the T-type calcium channels, which contribute to the automaticity of the sinoatrial and atrioventricular nodes $(7,8)$. Benzodiazepine receptors consist of central- and peripheral-type receptors (9). Peripheral-type benzodiazepine receptors, which are distributed to the peripheral tissues, including the cardiovascular system, have various functions, such as the regulation of voltage-dependent calcium channels (10). Benzodiazepine receptors are also divided into high-affinity and lowaffinity receptors; the former selectively bind in nanomolar concentrations of benzodiazepines, and the latter bind in micromolar concentrations and regulate voltage-sensitive calcium channels $(11,12)$. Clonazepam has been referred to as a specific agonist for the central-type receptor in contrast to diazepam, which is a non-specific agonist for both centraland peripheral-type receptors (7). Watabe et al. showed that clonazepam selectively blocks T-type calcium channels in micromolar concentrations, whereas diazepam blocks both L- and T-type calcium channels in a non-selective manner; those authors therefore concluded that T-type calcium channels are regulated by both central- and peripheral-type lowaffinity benzodiazepine receptors, although L-type calcium channels are regulated solely by peripheral-type low-affinity receptors (7). Clonazepam may therefore antagonize calcium channels despite the specific ligand for central-type benzodiazepine receptors.

The long-term administration of clonazepam in elderly patients with multiple comorbidities may lead to an overdosage and adverse drug events. Clonazepam is mainly metabolized in the liver, primarily by cytochrome P450 isoenzyme 3A4 $(4,13)$. Clonazepam is lipid-soluble and highly protein bound $(85 \%)$, and its elimination half-life is long (17-56 hours) $(4,13)$. In the present case, not only age-related decreases in the liver size, hepatic blood flow, and liver cytochrome P450 activity, but also complicated liver dysfunction due to chronic cholecystitis and total parenteral nutritioninduced fatty liver may have been associated with the decreased hepatic drug clearance of clonazepam. In addition, the cytochrome P450 levels and activities are reduced during infections and inflammation by up-regulated cytokines, such as interleukin 6 (14). With aging, the amount of body fat increases and the total body water decreases. Lipid-soluble drugs have an increased distribution volume in the elderly; therefore, drug accumulation and prolongation of the elimination half-life may occur with long-term administration (15). Age-dependent decreases in the serum albumin concentration influence the drug protein binding potency, and increases in the free concentration of highly proteinbound drugs may cause toxicity in patients with hypoalbuminemia (15). In addition, complicated subclinical hypothyroidism, likely caused by aging, may contribute to bradyarrhythmia.
Several limitations associated with the present study warrant mention. First, the serum clonazepam level at bradycardia onset was within the therapeutic range; however, we nevertheless considered the possibility of clonazepamassociated bradycardia because the condition disappeared after the drug was stopped. In a previous report, neither the therapeutic nor the side effects of clonazepam were clearly correlated with its serum concentration (1). For example, the serum clonazepam level was elevated to toxic levels in one case of clonazepam-associated atrioventricular block but not elevated in a case of clonazepam-associated sinus bradycardia $(5,6)$. Furthermore, advanced age is associated with an increased sensitivity to benzodiazepines, including clonazepam $(15,16)$. Thus, clonazepam-associated adverse events may occur even if the levels are within the normal range. If possible, the dose of clonazepam should be reduced to prevent adverse effects in elderly patients. Second, we did not examine the patient for ischemic heart disease. Considering the findings on her electrocardiograms, ischemic heart disease might have been concealed. An ischemic heart attack may have influenced the occurrence of bradycardia. A retrospective consecutive study of heart necropsy results reported severe coronary atherosclerosis in $8.7 \%$ of elderly Japanese individuals, $12 \%$ of whom had no history of ischemic heart disease (17). In addition, sinoatrial node dysfunction is often attributed to cardiac ischemia and idiopathic age-related fibrosis (18). However, we suspect that, in this elderly disabled woman, a thorough examination using coronary angiography may not have improved her prognosis. Third, cardiac conduction disturbances may also have been concealed in the present case. A previous electrocardiogram demonstrated multiple $\mathrm{P}$ wave contours, which may suggest sick sinus syndrome. Furthermore, ectopic atrial rhythm, sinoatrial block, and paroxysmal atrial fibrillation were observed after the cessation of clonazepam. Aging is associated with progressive fibrosis in both the sinoatrial node and atrioventricular conduction systems $(18,19)$. Previously concealed sinoatrial and atrioventricular conduction disturbance might have become apparent in the present patient through the action of clonazepam. Fourth, a chronic inflammatory state associated with gallstones and renal stones may have induced a transient fever and influenced the recovery of the patient's pulse rate. However, only the discontinuation of clonazepam clearly improved the severe bradycardia; the adverse effects of clonazepam may therefore have been a major cause of bradycardia. In disabled elderly individuals with multiple comorbidities, it may be difficult to fully elucidate their complicated pathophysiology affected by various clinical factors in an integrated manner.

Benzodiazepines, including clonazepam, may cause severe bradycardia. Benzodiazepines may have calcium channelblocking properties, which may explain the observed bradyarrhythmia. It is important for clinicians to be aware of benzodiazepine-associated bradycardia in order to prevent elderly patients from experiencing adverse drug events. 
The authors state that they have no Conflict of Interest (COI).

\section{References}

1. Pinder RM, Brogden RN, Speight TM, Avery GS. Clonazepam: a review of its pharmacological properties and therapeutic efficacy in epilepsy. Drugs 12: 321-361, 1976.

2. Masdrakis VG, Turic D, Baldwin DS. Pharmacological treatment of social anxiety disorder. Mod Trends Pharmacopsychiatri 29: 144-153, 2013.

3. Levy A, Chen R. Myoclonus: pathophysiology and treatment options. Curr Treat Options Neurol 18: 21, 2016.

4. Patsalos PN, Berry DJ, Bourgeois BF, et al. Antiepileptic drugsbest practice guidelines for therapeutic drug monitoring: a position paper by the subcommission on therapeutic drug monitoring, ILAE Commission on Therapeutic Strategies. Epilepsia 49: 12391276, 2008.

5. Arroyo Plasencia AM, Ballentine LM, Mowry JB, Kao LW Benzodiazepine-associated atrioventricular block. Am J Ther 19: e48-e52, 2012.

6. Hasegawa C, Narumiya H, Yamada H, Deguchi M. Bradycardia associated with concomitant amiodarone and clonazepam in dialysis patient. Medical Journal of Kyoto Second Red Cross Hospital 33: 68-72, 2012 (in Japanese, Abstract in English).

7. Watabe S, Yoshii M, Ogata N, Tsunoo A, Narahashi T. Differential inhibition of transient and long-lasting calcium channel currents by benzodiazepines in neuroblastoma cells. Brain Res 606: 244-250, 1993.

8. Mesirca P, Torrente AG, Mangoni ME. T-type channels in the sino-atrial and atrioventricular pacemaker mechanism. Pflugers Arch 466: 791-799, 2014.

9. Langer SZ, Arbilla S. Limitations of the benzodiazepine receptor nomenclature: a proposal for a pharmacological classification as omega receptor subtypes. Fundam Clin Pharmacol 2: 159-170, 1988.
10. Veenman L, Gavish M. The peripheral-type benzodiazepine receptor and the cardiovascular system. Implications for drug development. Pharmacol Ther 110: 503-524, 2006.

11. Bowling AC, DeLorenzo RJ. Micromolar affinity benzodiazepine receptors: identification and characterization in central nervous system. Science 216: 1247-1250, 1982.

12. Taft WC, DeLorenzo RJ. Micromolar-affinity benzodiazepine receptors regulate voltage-sensitive calcium channels in nerve terminal preparations. Proc Natl Acad Sci U S A 81: 3118-3122, 1984.

13. Riss J, Cloyd J, Gates J, Collins S. Benzodiazepines in epilepsy: pharmacology and pharmacokinetics. Acta Neurol Scand 118: 6986, 2008.

14. Williams JF. Cytochrome P450 isoforms. Regulation during infection, inflammation and by cytokines. J Fla Med Assoc 78: 517$519,1991$.

15. Mangoni AA, Jackson SH. Age-related changes in pharmacokinetics and pharmacodynamics: basic principles and practical applications. Br J Clin Pharmacol 57: 6-14, 2004.

16. Barnhill JG, Greenblatt DJ, Miller LG, Gaver A, Harmatz JS, Shader RI. Kinetic and dynamic components of increased benzodiazepine sensitivity in aging animals. J Pharmacol Exp Ther 253: 1153-1161, 1990.

17. Ohkawa S, Imai T, Ueda K, Shimada H, Sugiura M. Silent myocardial ischemia in the aged: a retrospective study from the evaluation of necropsy hearts. Jpn Circ J 53: 1414-1418, 1989.

18. Choudhury M, Boyett MR, Morris GM. Biology of the sinus node and its disease. Arrhythm Electrophysiol Rev 4: 28-34, 2015.

19. Kusumoto FM, Phillips R, Goldschlager N. Pacing therapy in the elderly. Am J Geriatr Cardiol 11: 305-316, 2002.

The Internal Medicine is an Open Access article distributed under the Creative Commons Attribution-NonCommercial-NoDerivatives 4.0 International License. To view the details of this license, please visit (https://creativecommons.org/licenses/ by-nc-nd/4.0/).

(C) 2017 The Japanese Society of Internal Medicine Intern Med 56: 2301-2305, 2017 